\title{
Çevre Kalitesi Açısından Yakınsama Hipotezine Yeni Bir Bakış: Ekolojik Ayak İzi ve Kulüp Yakınsamaya Dayalı Ampirik Bir Analiz*
}

\author{
A New Look to Convergence Hypothesis in Terms of Environmental Quality: \\ An Empirical Analysis Based on Ecological Footprint and Club Convergence
}

\section{Dr. Öğr. Üyesi Recep Ulucak}

Başvuru Tarihi: 26.07.2017

Kabul Tarihi: 19.03.2018

\section{Öz}

Çevre kalitesinin giderek bozulmasıla birlikte iktisatta çevreci bir dönüşüm süreci başlamış, çevre ekonomisi, doğal kaynaklar ekonomisi ve ekolojik iktisat gibi alanlar ilgi çekmeye başlamıştır. Bu çerçevede çevresel unsurları temsil eden değişkenler kullanılarak ekonometrik analizler yoluyla politika önerileri oluşturulmaya çalışılmaktadır. Ancak literatürde bu alanla ilgili önemli kısıtlardan bir tanesi de çevreyi temsil edecek kapsamlı bir değişkene ihtiyaç duyulmasıdır. Bu ihtiyaca yönelik olarak ekolojik ayak izinin son yillarda çevreyi kapsamlı bir şekilde temsil eden bir gösterge haline geldiği iddia edilmektedir. Dolayısıyla bu çalışma 1961-2009 dönemi için ekolojik ayak izi üzerinden çevresel yakınsama hipotezini test etmektedir. Bunun için Phillips ve Sul (2007) tarafindan özellikle panel gruplar için yakınsama hipotezini test etmek amacıyla geliştirilmiş olan ve ülkelerden kaynaklı heterojenliği dikkate alarak ortak özellikler taşıyan grupları kümeleyen kulüp yakınsama testi kullanılmaktadır. Elde edilen sonuçlar bir bütün olarak çevresel yakınsama hipotezinin geçerli olmadiğını ancak yakınsayan kulüplerin olduğunu göstermektedir.

Anahtar Kelimeler: Çevre Ekonomisi, Çevresel Yakınsama, Kulüp Yakınsama Analizi

\begin{abstract}
An ecological transformation has started in economics in conjunction with increasing environmental threats and conservationist fields attract great attention such as environmental economics, resources economics and Ecological economics. In this framework, policy recommendations have been made by using environmental variables through econometric analysis. However, an important constraint is that any variable that comprehensively represent the environment is neded. Fortunately, ecological footprint has been a comprehensive environmental indicator in recent years. This paper analyzes environmental convergence hypothesis by using ecological footprint data from 1961-2009. Panel Club convergence test allowing for a wide range of possible time paths and individual heterogeneity and clustering panels into club convergence groups developed by Phillips and Sul (2007) is used. Results disconfirm the environmental convergence hypothesis as a whole. Convergent clubs, however, are produced.
\end{abstract}

Keywords: Environmental Economics, Environmental Convergence, Club Convergence

Dr. Öğr. Üyesi Recep Ulucak, Erciyes Üniversitesi İ̈BF, r.ulucak@erciyes.edu.tr

* Bu çalışma aynı başlık altında EconAnadolu2017 konferansında özet olarak sunulmuştur. 


\section{Giris}

Ülkelerin ekonomik değerler açısından zamanla birbirine yakınsayacağ 1 ve aynı gelir düzeyine erişeceği hipotezi iktisat biliminin temel görüş ve varsayımlarının yol açacağı doğal bir sonuç olarak kabul edilir. Ancak bunun için ülkelerin sağlıklı bir iktisadi sistemin taşıması gereken özellikleri taşıması gerekmektedir. Sağlıklı bir İktisadi sistem inşa edildiğinde ekonomilerin dışa açıklığı, üretim faktörlerinin tam hareketli olması ve azalan verimler yasası faktörlerin getirisi az olan bölgelerden/ülkelerden getirisi fazla olan bölgelere/ülkelere taşınmasına yol açacak ve gelir düzeylerinin yakınsamasını sağlayacaktır. Üstelik sadece gelir düzeyi değil eğer piyasalar etkin bir şekilde tesis edilirse fiyatların da birbirine yakınsaması (tek fiyat kanunu) ve toplumların aynı satın alma gücüne ulaşması mümkün olacaktır. Modernizasyon teorisi bu bağlamda yakınsamayı sadece ekonomik değil çok daha geniş bir zemine taşımaktadır. $\mathrm{Bu}$ teori yakınsamayı küreselleşme ile açıklamaktadır. Teknoloji sayesinde iletişimin, ulaşımın, uluslararası finansal akışların ve ticaretin yaygınlaşmasının küresel entegrasyonu artıracağ 1 ve sadece ekonomik değil diğer sosyoekonomik ve kültürel değişkenlerin de benzer trendler izleyerek aynılaşacağı iddialarıyla açılamaktadır (LaFree, 2005, s.191).

İktisadi açıdan yakınsama analizleri gelir yakınsamasinı test etmek amaciyla Barro ve Sala-i-Martin (1992)'in çalışmasından sonra yaygınlaşmaya başlamış olsa da esasen Solow (1956) tarafından geliştirilmiş olan neoklasik büyüme modelinin bir uzantısıdır. Bir değişkenin başlangıç değeriyle sonraki dönem değerleri arasında negatif korelasyona dayalı olarak oluşturulan yakınsama denklemi daha sonra pek çok değişken için yakınsamanın test edildiği bir yöntem olarak benimsenmiştir. Mevcut literatürde yakınsama zaman serisi, panel veri veya yatay kesit formatında sıralanan veri gruplarına dayalı olarak pek çok konu için çalışılmaktadır. Bu çalışmalar emtia fiyatlarından kamu harcamalarına (sağlık, eğitim, askeri harcamalar vs), para ve maliye politikalarından dış ticaret, turizm ve enerji fiyatlarına kadar farklılık göstermektedir (Bukenya ve Labys 2005; Apergis vd. 2013; Wang 2009; Lau vd. 2016; Apergis 2015; Pjesky 2013; Chen vd. 2016; Ioana-Laura 2015; Su vd. 2014; Claustre ve Kehoe 2010; Solarin ve Lean 2014; Mishra ve Smyth 2014; Hao vd. 2015) ve her bir konu teorik olarak farklı mekanizmalar yardımıyla gerekçelendirilmektedir. Çevresel yakınsama da yakınsama lite- ratüründe son yıllarda önemli bir araştırma konusu haline gelmiştir. Özellikle 1950 sonrası artan iktisadi faaliyetlerin (üretim ve tüketim) yol açtığ 1 çevresel bozulmaların bir neticesi olarak dünyayı ciddi derecede tehdit eden küresel ısınma ve iklim değişikliği iktisat biliminde çevreci dönüşümlerin ortaya çımasına yol açmış ve çevre ekonomisi, ekolojik iktisat gibi akımların doğmasına yol açmıştır. Çevrenin büyüme modellerine dahil edilmesi (Acemoglu vd. 2012; Acemoglu vd. 2014; Brock ve Taylor, 2010; Howarth, 1998; Nordhaus, 1992; Reyes, 2011); ekonomik faktörlerin çevre üzerindeki etkisinin belirlenmesi (Grossman ve Krueger, 1991, 1995; Narayan ve Narayan, 2010; Yuan vd. 2016) bu süreçte çevreyle ilgili önemli araştırma konusu haline gelmiştir. Çevresel yakınsama da bu konulardan bir tanesidir.

Çevresel yakınsama ülkelerin sahip olduğu çevre kalitesinin zamanla birbirine yakınsayacağını iddia eder (Brock ve Taylor 2003, s. 2). Eğer ülkeler benzer üretim süreçlerinden geçip benzer gelir düzeylerine erişecekse çevre kalitesi açısından da aynı konuma gelecekleri varsayılır. Veya bir başka açıdan Birleşmiş Milletler gibi uluslararası örgütlerin son zamanlarda çevresel tehditler konusunda yapmış olduğu uyarılar ve almış olduğu kararların (Kyoto ve Paris İklim Anlaşması gibi) ülkeleri çevreye karşı daha bilinçli hale getireceği ve çevreyi korumaya yönelik ortak mücadeleyi teşvik edeceği konusundaki beklenti ülkelerin çevre kalitesinin zamanla yakınsayacağını teorik olarak desteklemektedir (Aldy, 2007, s. 353; Aldy, 2006, s. 534; Westerlund ve Basher, 2008, s. 110). Bu teorik zeminden hareketle çevrenin yakınsayıp yakınsamadığı ampirik çalışmaların araştırma konusu olmuştur pek çok çalışma çevre kirliliğini temsilen CO2 emisyonlarını kullanarak yakınsamayı çevresel açıdan analiz etmiştir. Strazicich ve List (2003), Aldy (2006, 2007), Brock ve Taylor (2010), Li ve Lin (2013), Wang vd. (2014), Presno vd. 2015), Tiwari vd. (2016), Apergis ve Payne (2017) bunlardan bazılar1dır. Literatürde çevreyi temsilen her ne kadar $\mathrm{CO} 2$ emisyonları kullanılsa da bu durum ciddi eleştirileri barındırmaktadır. Çünkü çevre kirliliği sadece $\mathrm{CO} 2$ emisyonlarından oluşmamaktadır. Toprak kirliliği, su kirliliği, orman ve diğer ekosistem alanlarının yok edilmesi gibi sorunlar göz ardı edilmemelidir (Arrow vd. 1995, s. 520). Ayrıca hükümetlerin Kyoto veya Paris sözleşmesi gibi anlaşmalardan ötürü $\mathrm{CO} 2$ emisyonuna yönelik uygulamaya koyduğu sıkı denetimler ve teknoloji sayesinde $\mathrm{CO} 2$ emisyonları azaltılırken di- 
ğer kirlilik unsurları artabilir. O yüzden çevreyi analiz eden çalışmalarda çevre kirliliğini sadece emisyon gibi hava kirliliği değil, daha kapsamlı şekilde temsil edecek bir değişken kullanılması önerilmektedir. Bu bakımdan ekolojik ayak izinin çok daha kapsamlı bir değişken olduğu iddia edilmektedir (Caviglia-Harris vd. 2009, s. 1149; Ulucak ve Lin, 2017, s. 337).

$\mathrm{Bu}$ çalışmanın amacı çevresel tahribatın göstergesi olarak ekolojik ayak izi değişkeni üzerinden çevresel yakınsama hipotezini test etmektir. Yapılan ön araştırmalara göre çevresel yakınsama hipotezinin ekolojik ayak izi değişkeni ile daha önce test edilmemiş olmasının çevresel yakınsama literatürüne önemli bir katkı sağlayacağı düşünülmektedir. Bu doğrultuda çalışmanın bundan sonraki kısımları, çevresel yakınsamaya yönelik literatür taraması, veri, yöntem, uygulama ve sonuç bölümlerinden oluşmaktadır.

\section{Literatür Taraması}

Çevresel yakınsama hipotezi literatürde önemli say1da ampirik çalışmanın konusu olmuştur. Bu çalışmalar çevre kirliliğini temsil etmek amacıyla kullanılan değişken ve/veya hipotezi test etmek amaciyla kullanılan yöntem açısından farklılık gösterdiği gibi uygulama için seçilen ülke grupları ve elde edilen sonuçlar açısından farklılık göstermektedir. Bazı çalışmalar yakınsamayı destekleyen bulgular elde ederken bazı çalışmalar yakınsamayı desteklemeyen sonuçlar elde etmiştir. Bu çalışmalara ait bilgiler özetle şu şekildedir. Strazicich ve List (2003) 1960-1997 aralığına ait CO2 emisyonlarını kullanarak 21 OECD ülkesi için çevresel yakınsama hipotezini yatay kesit ve panel birim kök analizleriyle incelemiş ve yakınsamayı destekleyen sonuçlar elde etmiştir. Aynı değişken üzerinden 1870-2028 dönemini Lanne ve Liski (2004) 16 ülke için yapısal kırılmalı panel birim kök testi ile sınamış ve hipotezi destekleyen ampirik bir bulguya ulaşamamışlardır. Nguyen Van (2005) 100 ülkeyi parametrik olmayan dağılım anaziyle 1966-1996 dönemi CO2 emisyonları üzerinden analiz etmiştir. Analiz 100 ülke için uygulandığında çevresel yakınsamaya dair sonuç elde edilememiştir ancak analiz sadece sanayileşmiş ülkelerin oluşturduğu örnekleme uygulandığında yakınsamayı destekleyen sonuçlar elde edilmiştir. Yine $\mathrm{CO} 2$ değerlerini kullanarak Aldy (2006) birim kök ve Markov dönüşüm matrisi analizleriyle 88 ülkenin oluşturduğu örneklemi 1960-
2000 dönemi için incelemiş ve 13 ülke için yakınsamayı destekleyen sonuçlar elde etmiştir. Analizde uzun dönemli emisyon tahminlerini kullandığında ise yakınsamanın aksine rraksamayı destekleyen sonuçlar elde etmiştir. Önceki çalışmalardan farklı olarak Camarero vd. (2008) çalışmasında çevresel performans endeksi (EPI) değerlerini kullanmış ve 1971-2002 dönemi için OECD ülkeleri veri zarflama ve SURADF birim kök yöntemleriyle analiz etmiştir. Buradan elde edilen sonuçlar yakınsamanın desteklendiği yönünde değerlendirilmiştir. Panopoulou ve Pantelidis (2009) yakınsamayı klüp yakınsama konseptinde ele almış ve Phillips ve Sul (2007) tarafından geliştirilen panel klüp yakınsama testini 128 ülkenin 1960-2003 arası CO2 değerlerine uygulamıștır. Elde edilen sonuçlar tüm ülkeler için genel bir yakınsamanın olmadığı ancak çeşitli gruplar açısından ülkelerin birbirine yakınsadığını doğrulamıştır. Benzer şekilde Herrerias (2013) aynı analizi 162 ülkenin 1980-2009 fosil yakıt kaynaklı CO2 değerlerine uygulamıştır ve yakınsamayı büyük bir grup için destekleyen sonuçlar elde etmiştir. Ancak aynı çalışmada ikili birim kök (pairwise unit root) analizi de uygulanmış ve bu analiz sonuçları ıraksamayı destekleyen bulgular üretmiştir. Li ve Lin (2013) yakınsamayı 110 ülkenin 1971-2008 dönemi CO2 verileri üzerinden panel GMM yöntemiyle analiz etmiş ve yakınsamayı destekleyen bulgular elde etmiştir. Wang vd. (2014) Çin’e bağlı şehirlerin 1995-2001 dönemi CO2 verileri üzerinden yakınsamayı Phillips ve Sul (2007) tarafından geliştirilen panel klüp yakınsama analiziyle test etmiş ve gruplar itibariyle yakınsamayı destekleyen sonuçlara ulaşırken tüm örneklem için yakınsamay1 destekleyen her hangi bir bulguya ulaşamamıştır. Burnett (2016) ise aynı analizi Amerika eyaletlerinin 1960-2010 dönemi verilerine uygulamış ve 26 eyalet için klüp yakınsama sonucuna ulaşırken diğer eyaletler sonuçların ıraksamayı gösterdiği sonucuna ulaşmıştır. Doğrusal olmayan zaman serisi ve panel birim kök testlerini kullanarak, Tiwari vd. (2016) 35 Sahra-altı Afrika ülkesinin 1960-2019 dönemi CO2 verilerini analiz etmiş ve zaman serisi analizinde 27 ülke için panel analizinde ise 15 ülke için yakınsamayı destekleyen sonuçlar elde etmişlerdir. Ahmed vd. (2016) 162 ülkenin 1960-2010 dönemi CO2 verilerini wavelet birim kök yöntemiyle analiz etmiş ve 38 ülke için yakınsamayı destekleyen sonuçlar elde ederken 124 ülke için ıraksama olduğu sonucuna ulaşmıştır. Apergis ve Payne (2017) klüp yakınsama konseptini takip ederek Amerika eyaletlerininin 1980-2013 
dönemi CO2 verilerini analiz etmiş ve bazı eyaletler yakınsarken bazı eyaletlerin ıraksadığı sonucunu elde etmişlerdir.

Literatürdeki çalışmalar incelendiğinde yakınsama hipotezinin test edilmesinde panel birim kök testleri yoğun bir şekilde kullanılmaktadır. Bunun dışında Phillips ve Sul (2007) tarafından geliştirilen panel klüp yakınsama testi de en çok kullanılan yöntemlerden biridir. Bir sonraki bölümde açıklanacağı üzere bu test yakınsamanın analiz edilmesinde birim kök testlerine göre daha avantajlıdır ve doğrudan yakınsama analizi yapmak için geliştirilmiştir. Bu yüzden bu çalışmada Phillips ve Sul (2007) klüp yakınsama testi kullanılacaktır. Mevcut literatürden farklı olarak bu çalışmada çevre kirliliğinin daha kapsamlı bir göstergesi olarak kabul edilen ekolojik ayak izi değişkeni kullanılacaktır.

\section{Veri, Yöntem ve Uygulama Sonuçları}

Ekolojik ayak izi Wachernagel ve Rees (1996) tarafından geliştirilmiştir ve beşeri faaliyetlerin çevre-doğa üzerindeki baskısını yansıtmaktadır (Bartelmus, 2008). Doğaya ve doğal kaynaklara olan talep veya biyosfere olan talep şeklinde de değerlendirilmektedir (Kitzes ve Wackernagel, 2009). Hesaplanmasinda sadece karbon emisyonları değil, tarım alanları, otlak alanlar, yapılaşma alanları, ormanlar, su alanları da dikkate alındığı için ekolojik ayak izi çevreyi temsil açısından $\mathrm{CO}_{2}$ 'ye göre daha kapsamlıdır. Bu bakımdan pek çok çalışma ekolojik ayak izini çevresel tahribatın ve çevresel sürdürülebilirliğin önemli bir göstergesi olarak değerlendirmektedir (Van Vuuren ve Smeets, 2000; Costanza, 2000; Haberl vd. 2001; Neumayer, 2004; Bartelmus, 2008; Cordero vd. 2008; Caviglia-Harris vd. 2009; Wiedmann vd Barrett, 2010; Bastianoni vd. 2012; Borucke vd. 2013; Wang vd. 2013; Al-Mulali vd. 2015; Hervieux vd Darné 2015; Ozturk vd. 2016).

Yakınsama analizi 120 ülkenin 1961-2009 dönemi için yıllık bazda kişi başı ekolojik izi verileri ile gerçekleştirilecektir. Veriler Global Footprint Network tarafından sağlanmıştır. 1961-2009 dönemine ait bazı ülkelerin verileri yetersiz olduğu için yakınsama analizi 120 ülke ile sinırlı tutulmuştur.

Bir değişkenin yakınsayıp yakınsamadığını test etmek amaciyla literatürde yoğun bir şekilde panel birim kök testleri kullanılmaktadır ve birim kökün varlığı yakınsamanın olmadığına işaret etmektedir (Islam, 2003, 335). Ancak panel birim kök testleri her bir ülke için analiz edilen değişkenin onu etkileyen diğer faktörlerden aynı şekilde etkilendiğini varsayar. Veya paneli oluşturan ülkelerin bir kısmı yakınsıyor olabilirken yakınsamayan ülke sayısının fazla olması durumunda yakınsamanın olmadığı sonucunu verir veya tam tersi. Dolayısıyla tüm ülkeler için elde edilen tek bir sonuçtan hareketle tüm ülkeler için aynı politika önerisi etkin olamaz (Herrerias 2013, s. 1142; Kurozumi vd. 2013, s. 2). Bu sikıntıları gidermek amacıyla Phillips ve Sul (2007) kümeleme yöntemi kullanarak analize dahil edilen ülkeleri veri matrisindeki benzerlikler açısından gruplandıran ve her bir grup veya klüp içerisinde yakınsamının olup olmadığını test eden klüp yakınsama analizini önermektedir. Log $t$ testi olarak adlandırılan bu analiz paneldeki verilerin birim kök özelliklerine dayanmamaktadır (Apergis ve Payne, 2017, s. 367). Panel veri formatındaki değişken 1 numaralı denklemde olduğu gibi iki bileşen ile gösterilmektedir

$y_{i t}=r_{i t} e_{t}$

$e_{t}$ kesitler arası ortak faktörü (common factor) gösterir ve $y_{i t}^{\prime}$ 'nin toplam ortak hareketini temsil eder. Örneğin bizim analizimizde ekolojik ayak izini etkileyecek $\mathrm{CO} 2$, fosil yakıtla vb. değişkenlerin etkisini yansıtır. $r_{i t}$ ise serideki kendine özgü bileşenleri temsil eder. Kesitlerin geçişsel faktörleri gibi. Daha sonra $r_{i t}$ 'nin her ülke için belirli bir $r_{i}$ değerine yakınsayacağ 1 varsayılır. Yakınsama hipotezini dikkate alarak $r_{i t}$ ve $r_{i}$ arasındaki mesafe zamanla $1 /\left(\left(\mathrm{t}^{a}\right) \log (\mathrm{t}+1)\right)$ oranında azalacaktır (her ülke için $\alpha \geq 0$ and $r_{i}=r$ ). Bu prosedür faktör yüklemelerinin $r_{i t}$ yakınsayıp yakınsamadığının kontrol edilmesiyle modelin yakınsayıp yakınsamadığının belirlenmesine yardımcı olmaktadır. Daha sonra geçiş yolu $h_{i t}$ yatay kesitlerin ortalamasıyla 2 numaralı denklem ile hesaplanır. Yatay kesitlerin ortalaması $\overline{\log _{t}}$, kişi başı değerlerin logaritmik değerleriyle oluşturulur.

$$
h_{i t}=\log y_{i t} / \overline{\log _{t}}
$$

2 numaralı denklemin uygulanmasindan sonra yatay kesit değişme oranı $H_{1} H_{t} 3$ numaralı denklem yardımıla hesaplanır.

$$
H_{t}=\frac{1}{N} \sum_{i=1}^{N}\left(h_{i t}-1\right)^{2}
$$


Her bir yatay kesit varyansının hesaplandığı 3 numaralı denklem panelin ortak değere olan uzaklığını göstermektedir. Daha sonra paneldeki her bir kesitin ortak değere yakınsayıp yakınsamadığı aşağıdaki hipotezlerle test edilir.

$H_{0}: r_{i}=r_{t}$ and $\alpha \geq 0$

$H_{A}: r_{i} \neq r_{t}$ and $\alpha<0$

Daha sonra 4 numaralı denklem ile gösterilen Log t regresyonu yardımıyla bu hipotezler istatistiki olarak test edilir.

$$
\begin{aligned}
& \log \left(H_{1} / H_{t}\right)-2 \log L(t)=c+b \log t+u_{t} \\
& \text { for } t=[\tau T],[\tau T]+1 \ldots, T \quad \tau>0
\end{aligned}
$$

$L(t)=\log (t)^{\prime}$ yi ve $\tau$ ise örneklemden çıkarılan oranı ifade etmektedir. Phillips and Sul (2007), $\tau=0.3$ alınmasını önermektedir. Kalıntıların uzun dönem varyansının elde edilmesinde değişen varyans ve otokorelasyon dikkate alınmaktadır. Yakınsamayı belirlemek için t testi kullanılır ve yüzde 5 anlamlılık düzeyi için t testi $<-1,65$ durumunda boş hipotez reddedilir. Boş hipotez nisbi/koşullu yakınsamay1 ifade etmekte ve panel veri için sigma yakınsama ile benzerlik göstermektedir (Phillips and Sul 2007). Eğer panelin tamamı için yakınsama bulunamazsa alt gruplar veya kulüpler için bakılır. Bunun için Phillips and Sul (2007) kümeleme yöntemi kullanmaktadır. Bunun için öncelile kesitler veya ülkeler son gözlemlerine göre sıralanır. Sonra $\mathrm{N}>\mathrm{k} \geq 2$ koşulu altında ( $\mathrm{k}$ seçilen kesit sayısı $\mathrm{N}$ toplam kesit sayısını ifade et-

\begin{tabular}{|c|c|c|c|c|}
\hline \multirow[t]{3}{*}{ Kulüp 1} & \multirow{3}{*}{$\begin{array}{l}\text { Tridinad Tobago, Namibya, Kuveyt, G.Kore, Ürdün, İran, } \\
\text { Ekv. Gine, Brunei } \\
\text { Toplam } 8 \text { Ülke }\end{array}$} & & katsayl & t istatistiği \\
\hline & & Sabit & -2.116 & -2.725 \\
\hline & & $\log t$ & 0.310 & 1.366 \\
\hline \multirow[t]{3}{*}{ Kulüp 2} & \multirow{3}{*}{$\begin{array}{r}\text { Vietnam, Suriye, Myanmar, Libya, İsrail, Cezayir } \\
\text { Toplam } 6 \text { Ülke }\end{array}$} & & katsayl & tistatistiği \\
\hline & & Sabit & -6.208 & -15.231 \\
\hline & & $\log t$ & 0.035 & 0.292 \\
\hline \multirow[t]{3}{*}{ Kulüp 3} & \multirow{3}{*}{$\begin{array}{l}\begin{array}{l}\text { Tayland, Papua Y. Gine, Pakistan, Nijerya, Malezya, } \\
\text { Lübnan, Irak, Gana, Mısır, Cibuti, Şili }\end{array} \\
\\
\end{array}$} & & katsayl & t istatistiğ $i$ \\
\hline & & Sabit & -6.322 & -9.018 \\
\hline & & $\log t$ & 0.223 & 1.088 \\
\hline \multirow[t]{3}{*}{ Kulüp 4} & \multirow{3}{*}{ 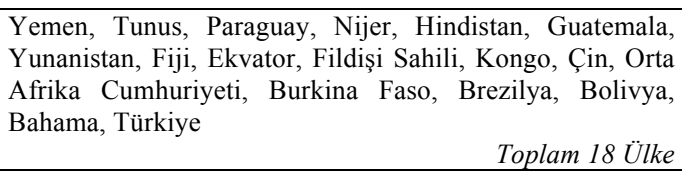 } & & katsayl & t istatistiği $i$ \\
\hline & & Sabit & -7.053 & -62.284 \\
\hline & & $\log t$ & 0.637 & 19.275 \\
\hline \multirow[t]{3}{*}{ Kulüp 5} & \multirow{3}{*}{$\begin{array}{l}\text { Venezuella, Uganda, Togo, Sudan, Srilanka, İspanya, } \\
\text { G.Afrika, Ruanda, Filipinler, Panama, Yeni Zelanda, Nepal, } \\
\text { Fas, Meksika, Moritanya, Mali, Liberya, K.Kore, Kenya, } \\
\text { İrlanda, Endonezya, Gine, Gine Bisav, Gambiya, Dominik, } \\
\text { Dem. Kongo Cumhuriyeti } \\
\text { Toplam } 26 \text { Ülke }\end{array}$} & & katsayl & t istatistiğ $i$ \\
\hline & & Sabit & -6.667 & -10.575 \\
\hline & & $\log t$ & 0.555 & 3.015 \\
\hline \multirow[t]{3}{*}{ Kulüp 6} & \multirow{3}{*}{$\begin{array}{l}\text { Zimbabve, ABD, Sierra leone, Senegal, Portekiz, Peru, } \\
\text { Nikaragua, Hollanda, Mozambik, İtalya, Honduras, El- } \\
\text { Salvador, Kosta Rika, Kolombiya, Kanada, Kamboçya, } \\
\text { Burundi, Bhutan, Barbados, Avustralya } \\
\\
\text { Toplam } 20 \text { Ülke }\end{array}$} & & katsayl & $t$ istatistiğ $i$ \\
\hline & & Sabit & -7.044 & -18.201 \\
\hline & & $\log t$ & 0.282 & 2.500 \\
\hline \multirow[t]{3}{*}{ Kulüp 7} & \multirow{3}{*}{$\begin{array}{lr}\text { Uruguay, İsviçre, Japonya, Guyana, Almanya, Fransa, } \\
\text { Finlandiya, Danimarka, Avusturya } \\
\end{array}$} & & katsayl & t istatistiğ $i$ \\
\hline & & Sabit & -6.815 & -13.631 \\
\hline & & $\log t$ & 0.837 & 5.736 \\
\hline \multirow[t]{3}{*}{ Kulüp 8} & \multirow{3}{*}{$\begin{array}{l}\text { İsveç, Romanya, Polanya, Norveç, Macaristan, Moğolistan, } \\
\text { Haiti, Küba, Bulgaristan, Belçika }\end{array}$} & & katsayl & t istatistiği \\
\hline & & Sabit & -10.112 & -16.948 \\
\hline & & $\log t$ & 1.814 & 10.419 \\
\hline
\end{tabular}

Tablo 1. Kulüp Yakınsama Test Sonuçları 
mektedir) en yüksek kesitler alt grup veya klubü GK oluşturmak için seçilir. Sonra log t testi bu alt grubun yakınsayıp yakınsamadığını test etmek için yeniden uygulanır ve alt grubun test istatistiğinin $\mathrm{k}$ üzerinden maksimizasyonuyla temel grup büyüklüğü belirlenir. Daha sonra dışarda kalan kesitler tek tek gruba dahil edilerek $\log \mathrm{t}$ testi yeniden uygulanır ve bu durumda $t$ istatistiği Phillips ve Sul'ün (2007) Monte Carlo çalışmaları ile oluşturdukları kritik değerler ile karşılaştırılır. t istatistiği önerilen kritik değerden büyük ise ilave edilen kesit gruba dahil edilir. Gruba dahil etmek veya etmemek için kalan diğer bütün kesitler için bu işlem gerçekleştirilir ve ilk yakınsayan kulüp oluşturulur. Daha sonra aynı işlemler ikinci, üçüncü (oluşabilecek maksimum kulüp sayısına kadar) kulüp için tekrar edilir.

Phillips ve Sul (2007) tarafından önerilen bu yöntemin 120 ülkenin 1961-2009 ekolojik ayak izi verilerine uygulanmasıyla elde edilen sonuçlar tablo l'de gösterilmiştir.

Herhangi bir kulübe giremeyen ve aralarında yakınsamanın olmadığı ülkeler ise şu şekildedir. İngiltere, Suudi Arabistan, Saint Lucia, Katar, Çad, Kamerun, Benin, Arjantin, Arnavutluk, Afganistan. Phillips ve Sul (2007) klüp yakınsama yöntemi öncelikli olarak genel bir yakınsamanın olup olmadığını test eder ve genel bir yakınsama yok ise yakınsayan kulüpleri belirler. Dolayısıyla yakınsama analizi sonuçlarına göre 120 ülke için genel bir yakınsama sonucu elde edilememiştir. Ancak kendi içerisinde yakınsayan 8 tane kulüp/küme oluşmuştur. Analiz sonucu oluşan kulüplere bakıldığında genel olarak hepsi ülkelerin sosyoekonomik yapıları açısından heterojenlik göstermektedir. Bu heterojenlik tüm ülkelerin çevresel sorunlara karşı ortak bir tavır sergilemesini zorlaştıracaktır.

\section{Sonuç}

Çevre açısından bugün karşı karşıya kalınan en önemli tehdit küresel ısınma ve iklim değişikliğidir. Bu sorunlarla mücadele etmek ülkelere çeşitli maliyetler yükleyeceği için gerekli önlemlerin alınması ve/veya yatırımların yapılması konusunda ülkeler yeterince hassas davranmamaktadır. Dolayısıyla bu soruna küresel çapta çözüm arayışları gerekmektedir. Nitekim Birleşmiş milletler öncülüğünde bu soruna yöne- lik çeşitli çözüm arayışları devam etmektedir. Kyoto Protokolü ve Paris İklim Anlaşması küresel ısınma ve iklim değişikliğini önlemeye en önemli küresel arayışlardır. Ancak en önemli sorun ülkelerin kirlilik konusunda birbirini suçlayarak bu arayışlar konusunda etkin bir uygulama alanı oluşturulamamasıdır. Çevre açısından ampirik olarak yakınsama sonucu ise ülkelerin bu tür mazeretlerini haksız çıkarmaya yönelik en önemli kanıtlardan bir tanesidir. Çünkü çevresel yakınsama ülkelerin çevre açısından zamanla aynı sürece gireceğini ifade etmektedir ve Ahmed vd (2016)'nin belirttiği gibi bu durumda yakınsayan ülkeler için ortak çevre politikalarının hayata geçirilmesi daha kolay hale gelmektedir. Aynı zamanda böyle bir durumda Westerlund ve Basher (2008)'in belirttiği gibi yakınsayan ülkelerin küresel çapta emisyon azatlımı gibi çevreye yönelik alınan kararlara katılımı ve mücadelesi daha kolay hale gelir. Bu bakımdan yakınsama hipotezi pek çok alanda olduğu gibi çevre açısından da önemli bir araştırma konusu olmuştur. Çünkü çevre kalitesi açısından ülkelerin birbirine yakınsayacağ 1 durumu çevreyi korumaya yönelik küresel politikaların başarısı konusunda bir ön değerlendirme imkânı sunmaktadır. Bu çalışmada çevresel yakınsama hipotezi 120 ülkenin ekolojik ayak izi verileriyle panel kulüp yakınsama analiziyle test edilmiş ve genel bir yakınsamanın aksine birbirine yakınsayan 8 kulüp/ küme elde edilmiştir. Elde edilen kulüpler incelendiğinde sosyoekonomik yapı açısından çok farklı olan ülkeler göze çarpmaktadır. Tüm ülkeler için genel bir yakınsamanın olmaması çevreyle ilgili ortak politikaların genel bir kabul görmeyeceği ve ülkeleri kirlilikle mücadelede motive etmeyeceği şeklinde değerlendirilmektedir. Dolayısıyla böyle bir durumda çevresel sorunlarla mücadelede ortak bir politikadan ziyade yakınsayan kulüpler itibariyle farklılaşan politikaların başarısı çok daha yüksek olacaktır.

\section{Kaynakça}

Acemoglu, D., Aghion, P., Bursztyn, L., \& Hemous, D. (2012). The Environment and Directed Technical Change. The American Economic Review, 102(1), 131-166. https://doi.org/10.1257/aer.102.1.131

Acemoglu, D., Akcigit, U., Hanley, D., \& Kerr, W. (2014). Transition to Clean Technology. Cambridge, MA. https://doi.org/10.3386/w20743 
Ahmed, M., Khan, A. M., Bibi, S., \& Zakaria, M. (2016). Convergence of per capita CO2 emissions across the globe: Insights via wavelet analysis. Renewable and Sustainable Energy Reviews. https:// doi.org/10.1016/j.rser.2016.10.053

Al-Mulali, U., Weng-Wai, C., Sheau-Ting, L., \& Mohammed, A. H. (2015). Investigating the environmental Kuznets curve (EKC) hypothesis by utilizing the ecological footprint as an indicator of environmental degradation. Ecological Indicators, 48, 315-323. https://doi.org/10.1016/j.ecolind.2014.08.029

Aldy, J. E. (2006). Per Capita Carbon Dioxide Emissions: Convergence or Divergence? Environmental \& Resource Economics, 33, 533-555. https://doi. org/10.1007/s10640-005-6160-x

Aldy, J. E. (2007). Divergence in state-level per capita carbon dioxide emissions. Land Economics, 83(3), 353-369. http://www.jstor.org/stable/27647777

Aldy, J. E. (2007). Divergence in State-Level Per Capita Carbon Dioxide Emissions. Land Economics, 83(3), 353-369. http://www.jstor.org/stable/27647777

Apergis, N. (2015). Convergence in Public Expenditure Across a Sample of Emerging Countries: Evidence from Club Convergence. Emerging Markets Finance and Trade, 51(3), 448-462. https://doi.org/ 10.1080/1540496X.2015.1025670

Apergis, N., Christou, C., \& Hassapis, C. (2013). Convergence in public expenditures across EU countries: evidence from club convergence. Economics \& Finance Research, 1(1), 45-59. https://doi.org/10.1 080/21649480.2013.862735

Apergis, N., \& Payne, J. E. (2017). Per capita carbon dioxide emissions across U.S. states by sector and fossil fuel source: Evidence from club convergence tests. Energy Economics. https://doi.org/10.1016/j. eneco.2016.11.027

Arrow, K., Bolin, B., Costanza, R., Dasgupta, P., Folke, C., Holling, C. S., ... Pimentel, D. (1995). Economic Growth, Carrying Capacity, and the Environment. Science, 268(5210).
Barro, R. J., \& Sala-i-Martin, X. (1992). Convergence. Journal of Political Economy, 100(2), 223-251. https://doi.org/10.1086/261816

Bartelmus, P. (2008). Quantitative eco-nomics: How sustainable are our economies? Quantitative Eco-nomics: How sustainable are our economies? Springer Netherlands.

Bastianoni, S., Niccolucci, V., Pulselli, R. M., \& Marchettini, N. (2012). Indicator and indicandum: "Sustainable way" vs "prevailing conditions" in the Ecological Footprint. Ecological Indicators, 16, 47-50. https://doi.org/10.1016/j.ecolind.2011.10.001

Borucke, M., Moore, D., Cranston, G., Gracey, K., Iha, K., Larson, J., ... Galli, A. (2013). Accounting for demand and supply of the biosphere's regenerative capacity: The National Footprint Accounts' underlying methodology and framework. Ecological Indicators, 24, 518-533. https://doi.org/10.1016/j. ecolind.2012.08.005

Brock, W. A., \& Taylor, M. S. (2003). THE KINDERGARTEN RULE OF SUSTAINABLE GROWTH (NBER No. Working Paper 9597). Massachusetts.

Brock, W. A., \& Taylor, M. S. (2010). The Green Solow model. Journal of Economic Growth, 15(2), 127153. https://doi.org/10.1007/s10887-010-9051-0

Burnett, J. W. (2016). Club convergence and clustering of U.S. energy-related $\mathrm{CO} 2$ emissions. Resource and Energy Economics, 46, 62-84. https://doi. org/10.1016/j.reseneeco.2016.09.001

Camarero, M., Picazo-Tadeo, A. J., \& Tamarit, C. (2008). Is the environmental performance of industrialized countries converging? A "SURE" approach to testing for convergence. Ecological Economics, 66(4), 653-661. https://doi.org/10.1016/j. ecolecon.2007.10.024

Caviglia-Harris, J. L., Chambers, D., \& Kahn, J. R. (2009). Taking the "U" out of Kuznets. A comprehensive analysis of the EKC and environmental degradation. Ecological Economics, 68(4), 1149-1159. https://doi.org/10.1016/j.ecolecon.2008.08.006 
Chen, Y., Cuestas, J. C., \& Regis, P. J. (2016). Convergence in Corporate Statutory Tax Rates in the Asian and Pacific Economies. International Journal of Finance \& Economics, 21(3), 266-278. https://doi. org/10.1002/ijfe.1546

Claustre Bajona, \& Kehoe, T. J. (2010). Trade, growth, and convergence in a dynamic HeckscherOhlin model. Review of Economic Dynamics, 13, 487-513. https://doi.org/10.1016/j.red.2010.05.002

Cordero, E. C., Marie Todd, A., Abellera, D., Cordero, E. C., Todd, A. M., \& Abellera, D. (2008). Climate Change Education and the Ecological Footprint. Bulletin of the American Meteorological Society, 89(6), 865-872. https://doi. org/10.1175/2007BAMS2432.1

Costanza, R. (2000). The dynamics of the ecological footprint concept. Ecological Economics, 32, 341-345. Retrieved from www.elsevier.com/locate/ecolecon

Grossman, G. M., \& Krueger, A. B. (1991). Environmental Impacts of a North American Free Trade Agreement. National Bureau of Economic Research Working Paper Series, No. 3914(3914), 1-57. https://doi.org/10.3386/w3914

Grossman, G. M., \& Krueger, A. B. (1995). Economic Growth and the Environment. The Quarterly Journal of Economics, 110(2), 353-377. https://doi. org $/ 10.2307 / 2118443$

Haberl, H., Erb, K.-H., \& Krausmann, F. (2001). How to calculate and interpret ecological footprints for long periods of time: the case of Austria 19261995. Ecological Economics, 38(1), 25-45. https:// doi.org/10.1016/S0921-8009(01)00152-5

Hao, Y., Wang, S., \& Zhang, Z.-Y. (2015). Examine the Convergence in Per Capita Energy Consumption in China with Breakpoints. Energy Procedia, 75, 2617-2625. https://doi.org/10.1016/j.egypro.2015.07.341

Herrerias, M. J. (2013). The environmental convergence hypothesis: Carbon dioxide emissions according to the source of energy. Energy Policy, 61, 11401150. https://doi.org/10.1016/j.enpol.2013.06.120
Hervieux, M. S., \& Darné, O. (2015). Environmental Kuznets Curve and ecological footprint: A time series analysis. Economics Bulletin, 35(1), 814-826. http://www.accessecon.com/Pubs/EB/2015/Volume35/EB-15-V35-I1-P84.pdf

Howarth, R. B. (1998). An Overlapping Generations Model of Climate-Economy Interactions. Scandinavian Journal of Economics, 100(3), 575-591. https://doi.org/10.1111/1467-9442.00123

Ioana-Laura, Ţ. (2015). Is there Evidence of Tax Convergence in the European Union? Procedia Economics and Finance, 32, 194-199. https://doi. org/10.1016/S2212-5671(15)01382-9

Islam, N. (2003). What have We Learnt from the Convergence Debate? Journal of Economic Surveys, 17(3), 309-362. https://doi.org/10.1111/14676419.00197

Kitzes, J., \& Wackernagel, M. (2009). Answers to common questions in Ecological Footprint accounting. Ecological Indicators, 9(4), 812-817. https://doi. org/10.1016/j.ecolind.2008.09.014

Kurozumi, E., Yamazaki, D., \& Hadri, K. (2013). COVARIATE UNIT ROOT TEST FOR CROSSSECTIONALLY DEPENDENT PANEL DATA (QUEEN'S MANAGEMENT SCHOOL ECONOMICS WORKING PAPER SERIES No. 2013-1). Retrieved from ftp://ftp.qub.ac.uk/pub/users/repec/qub/wpaper/MS_WPS_ECO_13_01.pdf

LaFree, G. (2005). Evidence For Elite Convergence in Cross-National Homicide Victimization Trends, 1956 to 2000. Sociological Quarterly, 46(1), 191-211. https://doi.org/10.1111/j.15338525.2005.00009.x

Lanne, M., \& Liski, M. (2004). Trends and Breaks in Per-Capita Carbon Dioxide Emissions, 1870-2028. The Energy Journal, 25(4). https://doi.org/10.5547/ ISSN0195-6574-EJ-Vol25-No4-3

Lau, C. K. M., Demir, E., \& Bilgin, M. H. (2016). A Nonlinear Model of Military Expenditure Convergence: Evidence From Estar Nonlinear Unit Root Test. Defence and Peace Economics, 27(3), 392-403. https://doi.org/10.1080/10242694.2015.1016296 
Li, X., \& Lin, B. (2013). Global convergence in per capita CO2 emissions. Renewable and Sustainable Energy Reviews, 24, 357-363. https://doi. org/10.1016/j.rser.2013.03.048

Mishra, V., \& Smyth, R. (2014). Convergence in energy consumption per capita among ASEAN countries. Energy Policy (Vol. 73). https://doi.org/10.1016/j. enpol.2014.06.006

Narayan, P. K., \& Narayan, S. (2010). Carbon dioxide emissions and economic growth: Panel data evidence from developing countries. Energy Policy (Vol. 38). https://doi.org/10.1016/j.enpol.2009.09.005

Neumayer, E. (2004). Indicators of Sustainability. In Thomas H. Tietenberg \& H. Folmer (Eds.), The International Yearbook of Environmental and Resource Economics 2004/2005 (pp. 139-189). Cheltenham: Edward Elgar.

Nguyen Van, P. (2005). Distribution Dynamics of CO2 Emissions. Environmental \& Resource Economics, 32(4), 495-508. https://doi.org/10.1007/s10640005-7687-6

Nordhaus, W. D. (1992). Lethal Model 2: The Limits to Growth Revisited. Brookings Papers on Economic Activity, 23(2), 1-60. https://www.brookings.edu/ wp-content/uploads/1992/06/1992b_bpea_nordhaus_stavins_weitzman.pdf

Ozturk, I., Al-Mulali, U., \& Saboori, B. (2016). Investigating the environmental Kuznets curve hypothesis: the role of tourism and ecological footprint. Environmental Science and Pollution Research, 23(2), 1916-1928. https://doi.org/10.1007/s11356015-5447-x

Panopoulou, E., \& Pantelidis, T. (2009). Club Convergence in Carbon Dioxide Emissions. Environmental and Resource Economics, 44(1), 47-70. https:// doi.org/10.1007/s10640-008-9260-6

Phillips, P. C. B., \& Sul, D. (2007a). Transition Modeling and Econometric Convergence Tests. Econometrica, 75(6), 1771-1855. https://doi.org/10.1111/ j.1468-0262.2007.00811.x
Phillips, P. C. B., \& Sul, D. (2007b). Transition Modeling and Econometric Convergence Tests. Econometrica, 75(6), 1771-1855. https://doi.org/10.1111/ j.1468-0262.2007.00811.x

Pjesky, R. J. (2013). Convergence In State And Local Spending On Education: Are Lotteries Ear Marked For Education The Key? Journal of Business \& Economics Research, 11(3), 137-146. https://cluteinstitute.com/ojs/index.php/JBER/article/download/7665/7730/

Presno, M. J., Landajo, M., \& Fernández González, P. (2015). Stochastic convergence in per capita $\mathrm{CO} 2$ emissions. An approach from nonlinear stationarity analysis. Energy Economics. https://doi. org/10.1016/j.eneco.2015.10.001

Reyes, R. C. (2011). The Green Solow model with natural resources constraint: A theoretical note. DLSU Business and Economics Review, 21(1), 111-116. http://www.dlsu.edu.ph/offices/publishing-house/ journals/ber/ber-publication.asp

Solarin, S. A., \& Lean, H. H. (2014). Nonlinearity convergence of tourism markets in Seychelles. Current Issues in Tourism, 17(6), 475-479. https://doi.org/1 $0.1080 / 13683500.2013 .810612$

Solow, R. M. (1956). A CONTRIBUTION TO THE THEORY OF ECONOMIC GROWTH. Source: The Quarterly Journal of Economics, 70(1), 65-94. Retrieved from http://www.jstor.org/stable/ 1884513

Strazicich, M. C., \& List, J. A. (2003). Are CO2 Emission Levels Converging Among Industrial Countries? Environmental and Resource Economics, 24(3), 263271. https://doi.org/10.1023/A:1022910701857

Su, C.-W., Chang, H.-L., Chang, T., \& Yin, K. (2014). Monetary convergence in East Asian countries relative to China. International Review of Economics \& Finance, 33, 228-237. https://doi.org/10.1016/j. iref.2014.05.008 
Tiwari, A. K., Kyophilavong, P., \& Albulescu, C. T. (2016). Testing the stationarity of CO2 emissions series in Sub-Saharan African countries by incorporating nonlinearity and smooth breaks. Research in International Business and Finance, 37, 527-540. https://doi.org/10.1016/j.ribaf.2016.01.005

Ulucak, R., \& Lin, D. (2017). Persistence of policy shocks to Ecological Footprint of the USA. Ecological Indicators, 80. https://doi.org/10.1016/j.ecolind.2017.05.020

Van Vuuren, D. P., \& Smeets, E. M. W. (2000). Ecological footprints of Benin, Bhutan, Costa Rica and the Netherlands. Ecological Economics, 34(1), 115-130. https://doi.org/10.1016/S0921-8009(00)00155-5

Wackernagel, M., \& Rees, W. (1996). Our Ecological Footprint: Reducing Human Impact on the Earth. The New Catalyst Bioregional Series. New Society Publishers.

Wang, Y., Han, R., \& Kubota, J. (2016). Is there an Environmental Kuznets Curve for SO2 emissions? A semi-parametric panel data analysis for China. Renewable and Sustainable Energy Reviews, 54, 11821188. https://doi.org/10.1016/j.rser.2015.10.143
Wang, Y., Kang, L., Wu, X., \& Xiao, Y. (2013). Estimating the environmental Kuznets curve for ecological footprint at the global level: A spatial econometric approach. Ecological Indicators, 34, 15-21. https://doi.org/10.1016/j.ecolind.2013.03.021

Wang, Y., Zhang, P., Huang, D., \& Cai, C. (2014). Convergence behavior of carbon dioxide emissions in China. Economic Modelling, 43, 75-80. https://doi. org/10.1016/j.econmod.2014.07.040

Westerlund, J., \& Basher, S. A. (2008). Testing for Convergence in Carbon Dioxide Emissions Using a Century of Panel Data. Environmental and Resource Economics, 40(1), 109-120. https://doi. org/10.1007/s10640-007-9143-2

Wiedmann, T., \& Barrett, J. (2010). A Review of the Ecological Footprint Indicator-Perceptions and Methods. Sustainability, 2(6), 1645-1693. https:// doi.org/10.3390/su2061645 